\title{
Self-declared stock ownership and association with positive trial outcome in randomized controlled trials with binary outcomes published in general medical journals: a cross-sectional study
}

Alberto Falk Delgado ${ }^{1,3^{*}}$ and Anna Falk Delgado ${ }^{2}$

\begin{abstract}
Background: Describe the prevalence and types of conflicts of interest (COI) in published randomized controlled trials (RCTs) in general medical journals with a binary primary outcome and assess the association between conflicts of interest and favorable outcome.

Methods: Parallel-group RCTs with a binary primary outcome published in three general medical journals during 2013-2015 were identified. COI type, funding source, and outcome were extracted. Binomial logistic regression model was performed to assess association between $\mathrm{COI}$ and funding source with outcome.

Results: A total of 509 consecutive parallel-group RCTs were included in the study. COI was reported in $74 \%$ in mixed funded RCTs and in 99\% in for-profit funded RCTs. Stock ownership was reported in none of the non-profit RCTs, in 7\% of mixed funded RCTs, and in 50\% of for-profit funded RCTs. Mixed-funded RCTs had employees from the funding company in $11 \%$ and for-profit RCTs in $76 \%$. Multivariable logistic regression revealed that stock ownership in the funding company among any of the authors was associated with a favorable outcome (odds ratio $=3.53 ; 95 \%$ confidence interval $=1.59-7.86 ; p<0.01$ ).
\end{abstract}

Conclusion: $\mathrm{COI}$ in for-profit funded RCTs is extensive, because the factors related to COI are not fully independent, a multivariable analysis should be cautiously interpreted. However, after multivariable adjustment only stock ownership from the funding company among authors is associated with a favorable outcome.

Keywords: Randomized controlled trials, RCTs, Industry funding, Conflict of interest, Employment, Stock ownership

\section{Background}

Randomized controlled trials (RCTs) financed by industry (for-profit) are associated with more favorable outcomes compared with other types of funding sources [1], partly explained by the usage of surrogate endpoints (e.g. biochemical, imaging) among trials financed by industry [2]. Furthermore, declared conflict of interest (COI) among authors of clinical trials has been

\footnotetext{
* Correspondence: Alberto.Falk-Delgado@surgsci.uu.se

${ }^{1}$ Department of Surgical Sciences, Uppsala University, Uppsala, Sweden

${ }^{3}$ Ing. 78/79, Plastikmottagningen, Uppsala University Hospital, Akademiska sjukhuset, 75185 Uppsala, Sweden

Full list of author information is available at the end of the article
}

associated with favorable study conclusions [3-5]. To increase transparency in medical research, the International Committee of Medical Journal Editors (ICMJE) developed, in 2009, an electronic form of financial disclosure to establish uniform reporting of competing interests with the submission of manuscripts, today mandatory in most journals. The form includes, among others, the reporting of personal fees, employment, royalties, stock ownership and grants in order for the reader to consider each potential relationship between author and industry [6].

Most of the previous work evaluating COI and its effect on outcome was performed before the introduction 
of structured disclosure forms, which are now mandatory in most journals [7]. More recently, it was shown that studies on interventional cardiology devices with industry employees among authors were more likely to report favorable outcomes [8]. The impact of COI on RCT study outcome is, however, still unclear. Further, it has not been established how different type of COIs might impact outcome in RCTs.

We performed a cross-sectional study to evaluate the prevalence and types of conflicts of interest in published randomized controlled trials (RCTs) in general medical journals with a binary primary outcome and to assess the association between conflicts of interest and favorable outcome.

\section{Methods}

An experienced librarian conducted a systematic search identifying all RCTs published in three general medical journals: Journal of the American Medical Association, The Lancet, and the New England Journal of Medicine from January 2013 to September 2015, as previously reported [9]. The search was conducted by using the following expanded search terms: JAMA, Lancet, $N$ Engl J $M e d$, and randomized OR randomized and filtering for 2013/01/01 and 2015/09/23. One author (AlFD) reviewed the titles and abstracts of all potential studies for inclusion. The following inclusion criteria were used: RCTs, parallel-group studies with a binary outcome. We considered a study to be randomized if the term random was mentioned in the methods section of the published article. The study was conducted according to the PRISMA checklist (Additional file 1). The following exclusion criteria were used: letters, abstracts, editorials, non-RCTs, and multi-arm-RCTs. Studies with a continuous variable as primary endpoint were excluded. Financial relationship was defined according to the definition reported in the ICMJE COI form, with relevant COI directly related to for-profit organizations and linked to the submitted work [10]. A study was reported as having COI if any of the authors had a disclosure of COI. Data extraction was performed by one author (AIFD). Data extraction was performed for type of COI, funding source, and study outcome in a blinded manner. Study outcome was assessed first without knowledge of funding and COI. Then COI and funding were extracted blinded for outcome. Studies were classified as having a positive/negative study outcome based on being statistically significant in favor of the intervention compared with the control group in relation to the study primary outcome. All data were double-checked by one author (AnFD). COI was extracted from published papers or online supplements. The following COI types are included in the electronic ICMJE disclosure form if applicable: grants, personal fees, financial support, other, pending patent, issued patent, licensed patent, royalties, stock ownership, and employee. We only considered self-declared COI in the study. This study was not registered in Prospero since the outcome was not related to patient or clinical outcome [11].

\section{Statistical analysis}

We compared all trial variables between the different funding sources (non-profit, mixed profit, and forprofit); non-profit was defined as reference, using odds ratio (OR) and Fisher's exact test. Pre-specified analyses of factors (COI and funding source) potentially influencing the study outcome were evaluated with binomial simple and multivariable logistic regression. In the regression model, the dependent variable was outcome (positive/negative) and the independent variables were: grants (yes/no), personal fee (yes/no), financial support (yes/no), other (yes/no), pending patent (yes/no), issued patent (yes/no), licensed patent (yes/no), royalties (yes/ no), stockholder (yes/no), employee (yes/no), and funding source (for-profit/non-profit/mixed). Variables with a $p$ value less than 0.2 in the univariable model were kept in the multivariable model. Unadjusted and adjusted ORs were reported with 95\% confidence intervals (CIs). Interactions in the model were explored. Interaction terms with dummy variables were used to test for significant interactions between funding source and all COI subtypes in the logistic regression model. The goodness of fit in the logistic regression model was evaluated with Hosmer-Lemeshow test. All $p$ values were two-tailed, with significance defined as $p<0.05$. All statistical tests were performed using SPSS software (version 20, SPSS Inc., Chicago, IL, USA).

\section{Results}

\section{Description of included studies}

The electronic search retrieved 1149 hits. A total of 509 consecutive parallel-group RCTs met the inclusion criteria, as previously reported (Fig. 1) [9]. There were no missing data regarding COI or funding, $48 \%$ of the studies were funded by non-profit, $23 \%$ were mixed funded, and $29 \%$ were funded by for-profit organizations. A full description of the prevalence of COI, COI subtypes and funding source are presented in Table 1 and Additional file 2. COI related to any of the authors was reported in $50 \%$ of the studies. Out of these, $55 \%$ had a favorable study outcome.

The prevalence of COI varied depending on funding. Any type of COI was found in $99 \%$ of for-profit funded RCTs $(p<0.01$ compared with non-profit), $74 \%$ of mixed funded RCTs $(p<0.01$, compared with non-profit), and in $8 \%$ of non-profit RCTs. Personal fees were reported in $88 \%$ of for-profit RCTs $(p<0.01$ compared with non-profit), $53 \%$ in mixed $(p<0.01$ 


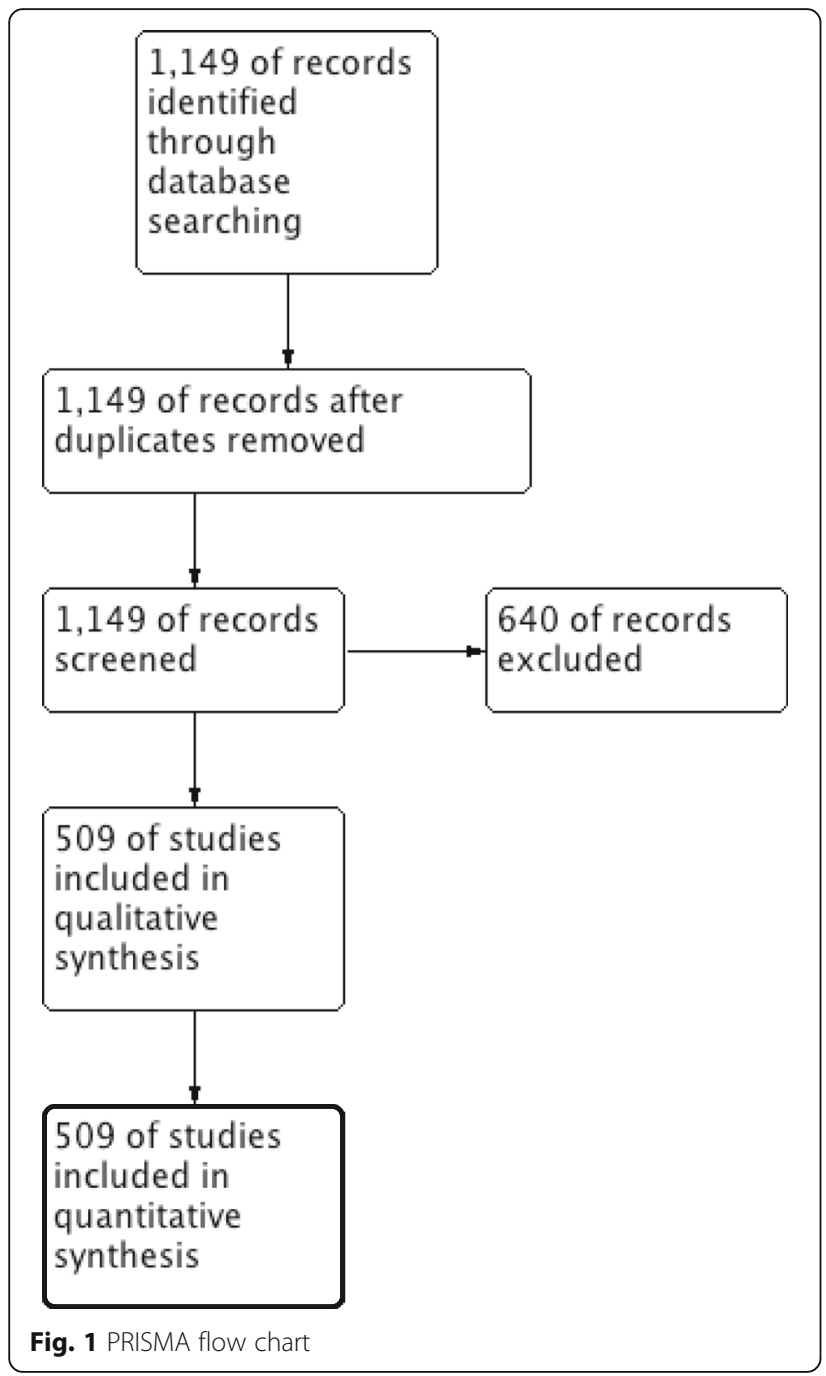

compared with non-profit), and 3\% of non-profit RCTs. Stock ownership was reported in in $50 \%$ of for-profit funded RCTs $(p<0.01$ compared with nonprofit), in $7 \%$ of mixed funded RCTs ( $p=0.02$ compared with non-profit), and none of the non-profit RCTs. For-profit RCTs had employees from the funding company as authors in $76 \%(p<0.01$ compared with non-profit), and mixed-funded RCTs in $11 \%$ ( $p<$ 0.01 compared with non-profit).

\section{Univariable logistic regression and association with favorable outcome}

Table 2 shows the association between a favorable outcome and a specific type of COI with the related effect size. Univariable logistic regression revealed that a favorable outcome was more common with the presence of the following COI: grant, personal fee, other, stock ownership, employee, mixed/for-profit funding.

\section{Multivariable logistic regression and association with} favorable outcome

The effect of COI after multivariable logistic regression analysis revealed that only stock ownership was more likely associated with a favorable outcome $(\mathrm{OR}=3.53$, 95\% CI $=1.59-7.86, p<0.01$ ) compared with studies without stock ownership in the funding company. Hosmer-Lemeshow test revealed $p=0.46$ for goodnessof-fit for the model, indicating a good fit of the model (Table 3). In the multivariable logistic regression model, there were no associations between a favorable outcome and any of the other types of COI or funding source. No significant interaction between any of the factors in the logistic regression model were found.

\section{Discussion}

Authors of industry-sponsored parallel-group RCTs published in 2013-2015 in three general medical journals report extensive COIs, in particular personal fees received from the funding source, employment in the funding company, and stock ownership in the funding company. Multivariable analysis showed that stock ownership among authors were associated with a favorable study outcome. This is to our knowledge the first study to describe the structure and composition of COI where we report that stock ownership and positive outcomes are associated after multivariable adjustment.

All included papers reported on conflict of interest in the published manuscript or this information could be retrieved from the corresponding online supplementary material. This is a substantial improvement compared with approximately $0.5-2 \%$ COI reported almost 20 years ago [12, 13]. Given this historic under-reporting of COI, the structure and composition of financial disclosure has been mainly unknown. In our material, $99 \%$ of profitfunded research reported COI. Previous studies based on publications in the top-tier journals in 2000-2008 reported that COI was present in $75 \%$ of industrysponsored studies [7], the contemporary higher prevalence can be associated with more accurate reporting of financial disclosures.

Few publications have focused on associations between different COI domains and favorable outcome. Employment of the funding company was recently shown to be associated with favorable outcome in studies on cardiology interventional devices [8]. Employment was associated with favorable outcome in the univariable analysis in our study, but not after adjusting for the other factors in the model. This difference might be explained by our inclusion of different COI subtypes and adjustment for this in the model. Stock ownership among authors has previously not been linked to more favorable outcome [7], possibly explained by a previous under-reporting of disclosures [14]. In univariable analysis several of the 
Table 1 Funding source and conflict of interest

\begin{tabular}{|c|c|c|c|c|c|}
\hline & Non-profit & Mixed funding & & For-profit & \\
\hline & $n=244$ & $n=117$ & & $n=148$ & \\
\hline & n (\%) & n (\%) & $p$ value & n (\%) & $p$ value \\
\hline COI present (any) & $20(8)$ & $86(74)$ & $<0.01$ & $147(99)$ & $<0.01$ \\
\hline \multicolumn{6}{|l|}{ Type of COI } \\
\hline Grant & $3(1)$ & $62(53)$ & $<0.01$ & $117(79)$ & $<0.01$ \\
\hline Personal fee & $8(3)$ & $62(53)$ & $<0.01$ & $130(88)$ & $<0.01$ \\
\hline Financial support & $5(2)$ & $30(26)$ & $<0.01$ & $75(51)$ & $<0.01$ \\
\hline Other & 0 & $13(11)$ & $<0.01$ & $62(42)$ & $<0.01$ \\
\hline Pending patent & $4(2)$ & $6(5)$ & 0.08 & $6(4)$ & 0.15 \\
\hline Issued patent & $1(0)$ & $4(3)$ & 0.06 & $10(7)$ & $<0.01$ \\
\hline Licensed patent & $4(2)$ & $7(6)$ & 0.04 & $8(5)$ & 0.05 \\
\hline Royalties & $2(1)$ & $2(2)$ & 0.46 & $4(3)$ & 0.17 \\
\hline Stock ownership & $0(0)$ & $7(6)$ & 0.02 & $74(50)$ & $<0.01$ \\
\hline Employee & $0(0)$ & $13(11)$ & $<0.01$ & $113(76)$ & $<0.01$ \\
\hline
\end{tabular}

COI domains (grants, personal fee, financial support, other, stockholder, employee, mixed funding, and forprofit funding) were significantly more likely associated with a positive outcome. After adjusting for COI subtype and funding source, there was only one significant remaining effect (stock ownership). Stock ownership among any of the authors were associated with a favorable outcome. Our results are in contrast with previous studies that have shown that for-profit are associated with favorable outcomes $[3,4]$. Compared with previous studies $[3,4,7]$, we included COI subtypes and funding sources in a multivariable model allowing for adjustments for possible interactions between variables. Stock ownership was almost exclusively reported in forprofit sponsored studies. However, no significant interaction was found in the model after exploring between funding source and COI domains.

Stock ownership is a special type of COI since a positive outcome of a trial might directly result in an increase in the company's stock price compared with, for example, a personal fee for conducting a study that does not necessarily result in future revenues depending on the outcome of the study. Stocks for employees are commonly used to attract and keep the employee within the

Table 2 Association of industry financial COI and outcome (dependent variable), after univariable binomial logistic regression

\begin{tabular}{llll}
\hline COI (any author, $n$ studies) & Favorable outcomes, $\mathrm{n}(\%)$ & Unadjusted OR for a favorable outcome $(95 \% \mathrm{Cl})$ & $p$ value \\
\hline Grants (182) & $104(57)$ & $2.05(1.42-2.96)$ & $<0.01$ \\
Personal fee (200) & $110(55)$ & $1.85(1.29-2.65)$ & $<0.01$ \\
Financial support (110) & $59854)$ & $1.50(0.98-2.29)$ & 0.06 \\
Other (99) & $66(67)$ & $2.91(1.83-4.62)$ & $<0.01$ \\
Pending patent (16) & $10(63)$ & $2.02(0.72-5.64)$ & 0.18 \\
Issued patent (15) & $10(67)$ & $1.66(0.66-4.20)$ & 0.11 \\
Licensed patent (19) & $11(58)$ & $0.71(0.17-2.99)$ & 0.28 \\
Royalties (8) & $3(38)$ & $4.54(2.64-7.80)$ & 0.64 \\
Stock ownership (81) & $61(75)$ & $2.86(1.88-4.36)$ & $<0.01$ \\
Employee (126) & $82(65)$ & & $<0.01$ \\
Funding source & & Reference & $<0.01$ \\
$\quad$ Non-profit (244) & $93(38)$ & $2.51(1.53-4.14)$ & $<0.01$ \\
$\quad$ Mixed (117) & $47(40)$ & $2.74(1.80-4.19)$ & \\
For-profit (148) & $93(63)$ & & \\
\hline
\end{tabular}


Table 3 Association of industry financial conflict of interest with outcome (dependent variable), after multivariable adjustments (binomial logistic regression)

\begin{tabular}{lll}
\hline COI (any author) & $\begin{array}{l}\text { Adjusted OR for a favorable outcome }(95 \% \\
\text { Cl) }\end{array}$ & $\begin{array}{l}p \\
\text { value }\end{array}$ \\
\hline Grants & $1.35(0.74-2.45)$ & 0.32 \\
Personal fee & $0.89(0.48-1.64)$ & 0.70 \\
Financial & $0.63(0.36-1.11)$ & 0.11 \\
support & $1.51(0.74-3.09)$ & \\
Other & $1.94(0.52-7.30)$ & 0.26 \\
Pending patent & 0.33 \\
Issued patent & $0.78(0.19-3.25)$ & 0.78 \\
Stockholder & $3.53(1.59-7.86)$ & $<0.01$ \\
Employee & $0.79(0.32-1.96)$ & 0.61 \\
Funding source & & 0.37 \\
Non-profit & Reference & \\
Mixed & $0.63(0.27-1.45)$ & 0.27 \\
For-profit & $1.02(0.57-1.82)$ & 0.95 \\
\hline COl conflict of intest
\end{tabular}

$\mathrm{COI}$ conflict of interest

company and function as economic incentive to profit from any market price rise. Half of all industry-financed studies have at least one author with stocks in the funding company and it is possible that this direct financial conflict and incentive might affect judgment and hamper scientific integrity of the data, with strategic and moral reason to inflate advice $[15,16]$. Bias related to COI might be related to unconscious motivational processes $[17,18]$. Several mechanisms on how positive outcomes can be achieved have been proposed, for example by statistical analysis such as randomization procedures, parametric analyses, run-in enrichments technique, and dichotomizing of ordered data [19]. This study highlights the strong connection between industry and COI and it can be discussed if this tight bond might jeopardize scientific validity of the studies. Studies report COI balance between science, advertisement, and revenue.

Translating our findings into a policy change, we do believe it important that the community is aware of the actual disclosure rates in the studies and type of financial disclosures. Since different COI domains might be related to favorable outcomes, this is a useful tool to critically appraise trial reports. Authorization of stock ownership by trial authors might still be accepted but needs to be discussed in a broader context in the future.

Limitations of this study needs to be addressed. As we only considered self-declared COI, there is a potential of underreporting of the actual COI that might exist as shown previously [20].

Furthermore, we included all randomized studies that mentioned the term "random" in the methods section. Since this can include studies with vague description of their randomization procedure, this is a further limitation of our study [21]. Study selection always introduces bias and our selection of trials published in highly cited journals with a high proportion of industry-sponsored trials might have introduced bias. It is possible that for-profit financed RCTs published in high impact journals are the first major trials published for a novel treatment and early positive trials tend to have larger effect sizes than later ones [22]. Thus, the generalizability of COI to lower impact journals cannot be ascertained. Further, we included only parallel-group RCTs with binary outcomes such as survival, progression-free survival and myocardial infarction, excluding studies with continuous variables since we consider that it is relatively more difficult to obtain a statistical significant result for binary outcomes since they are more often related to a clinical endpoint rather than surrogate endpoint [23] and to establish more comparable study groups. Furthermore, parallel-group RCTs were exclusively included to simplify the assessment of a favorable outcome, compared with a multi-arm RCT. However, we acknowledge that this further limits the generalizability of the study.

The prevalence of royalties and patents among authors was low in our cohort and not associated with positive outcome.

\section{Conclusions}

COI in for-profit funded RCTs is extensive with several COI domains associated with favorable outcomes: because the factors related to COI are not fully independent, a multivariable analysis should be cautiously interpreted. However, only stock ownership from the funding company among authors was related to a favorable outcome. Future studies should address the structure and mechanism on how stock ownership among authors in RCTs affect outcome.

\section{Additional files}

Additional file 1: PRISMA checklist. (DOC 62 kb)

Additional file 2: Review protocol and raw data. (XLS 194 kb)

Abbreviations

COI: Conflict of interest; RCT: Randomized controlled trial

\section{Acknowledgements}

The authors thank the reviewers and editor for improving the manuscript.

Funding

None

Availability of data and materials

All data is available online with this submission. 


\section{Authors' contributions}

AnFD and AlFD planned the study. AnFD and AIFD analyzed the data. Both the authors had full access to all of the data in the study and takes responsibility for the integrity of the data and the accuracy of the data analysis. Both authors read and approved the final manuscript.

\section{Ethics approval and consent to participate}

Not applicable

\section{Consent for publication}

Not applicable

\section{Competing interests}

The authors declare that they have no competing interests.

\section{Publisher's Note}

Springer Nature remains neutral with regard to jurisdictional claims in published maps and institutional affiliations.

\section{Author details}

'Department of Surgical Sciences, Uppsala University, Uppsala, Sweden. ${ }^{2}$ Department of Clinical Neuroscience, Karolinska Institute, Stockholm, Sweden. ${ }^{3}$ Ing. 78/79, Plastikmottagningen, Uppsala University Hospital, Akademiska sjukhuset, 75185 Uppsala, Sweden.

Received: 8 March 2017 Accepted: 14 July 2017

Published online: 26 July 2017

\section{References}

1. Ridker PM, Torres J. Reported outcomes in major cardiovascular clinical trials funded by for-profit and not-for-profit organizations: 2000-2005. JAMA. 2006:295(19):2270-4

2. Roper $\mathrm{N}$, Zhang $\mathrm{N}$, Korenstein D. Industry collaboration and randomized clinical trial design and outcomes. JAMA Intern Med. 2014:174(10):1695-6.

3. Bekelman JE, Li Y, Gross CP. Scope and impact of financial conflicts of interest in biomedical research: a systematic review. JAMA. 2003;289(4):454-65.

4. Lundh A, Sismondo S, Lexchin J, Busuioc OA, Bero L. Industry sponsorship and research outcome. Cochrane Database Syst Rev. 2012;12:MR000033.

5. Kjaergard LL, Als-Nielsen B. Association between competing interests and authors' conclusions: epidemiological study of randomised clinical trials published in the BMJ. BMJ. 2002;325(7358):249.

6. Drazen $\mathrm{JM}$, et al. Uniform format for disclosure of competing interests in ICMJE journals. N Engl J Med. 2009:361(19):1896-7.

7. Aneja A, Esquitin R, Shah K, lyengar R, Nisenbaum R, Melo M, et al. Authors' self-declared financial conflicts of interest do not impact the results of major cardiovascular trials. J Am Coll Cardiol. 2013;61(11):1137-43.

8. Smilowitz NR, Pirmohamed A, Weisz G. Published articles reporting studies by industry employees on interventional cardiology devices: scope and association with study outcomes. JAMA Intern Med. 2016;176(5):706-8.

9. Falk Delgado A, Falk DA. The association of funding source on effect size in randomized controlled trials: 2013-2015 - a cross-sectional survey and metaanalysis. Trials. 2017;18(1):125

10. ICMJE. http://icmje.org/conflicts-of-interest/. Accessed 2 Mar 2017

11. Prospero International Prospective Register of Systematic Reviews. https:// www.crd.york.ac.uk/PROSPERO/. Accessed 2 Mar 2017.

12. Hussain A, Smith R. Declaring financial competing interests: survey of five general medical journals. BMJ. 2001;323(7307):263-4.

13. Krimsky S, Rothenberg LS. Conflict of interest policies in science and medical journals: editorial practices and author disclosures. Sci Eng Ethics. 2001;7(2):205-18.

14. Kesselheim AS, Wang B, Studdert DM, Avorn J. Conflict of interest reporting by authors involved in promotion of off-label drug use: an analysis of journal disclosures. PLoS Med. 2012;9(8):e1001280.

15. Cain DM, Loewenstein G, Moore DA. The dirt on coming clean: perverse effects of disclosing conflicts of interest. J Legal Stud. 2005:34(1):1-25.

16. Cain DM, Loewenstein G, Moore DA. When sunlight fails to disinfect: Understanding the perverse effects of disclosing conflicts of interest. Consum Res. 2011;37(5):836-57.

17. Moore DA, Loewenstein G. Self-interest, automaticity, and the psychology of conflict of interest. Soc Justice Res. 2004;17(2):189-202.
18. Dana J, Loewenstein G. A social science perspective on gifts to physicians from industry. JAMA. 2003:290(2):252-5.

19. Berger WW. Conflicts of interest, selective inertia, and research malpractice in randomized clinical trials: an unholy trinity. Sci Eng Ethics. 2015:21(4):857-74.

20. Policy and Medicine. http://www.policymed.com/2009/03/jama-editor-callscritic-a-nobody-and-a-nothing.html.

21. Berger W, Bears JD. When can a clinical trial be called 'randomized'? Vaccine. 2003;21(5-6):468-72

22. Pereira TV, Horwitz RI, loannidis JP. Empirical evaluation of very large treatment effects of medical interventions. JAMA. 2012;308(16):1676-84.

23. Ia Cour JL, Brok J, Gotzsche PC. Inconsistent reporting of surrogate outcomes in randomised clinical trials: cohort study. BMJ. 2010;341:c3653.

\section{Submit your next manuscript to BioMed Central} and we will help you at every step:

- We accept pre-submission inquiries

- Our selector tool helps you to find the most relevant journal

- We provide round the clock customer support

- Convenient online submission

- Thorough peer review

- Inclusion in PubMed and all major indexing services

- Maximum visibility for your research

Submit your manuscript at www.biomedcentral.com/submit
Biomed Central 